\title{
Effect of Plasma Fluorination Variables on the Deposition and Growth of Partially Fluorinated Polymer Over PMMA Films
}

\author{
Giovana da Silva Padilha \\ School of Food Engineering, State University of Campinas - UNICAMP \\ Virginia Mansanares Giacon \\ Federal University of Amazonas - UFAM \\ Julio Roberto Bartoli \\ School of Chemical Engineering, State University of Campinas - UNICAMP
}

\begin{abstract}
In this work, an investigation was made of the modification of film surface of Poly(methylmethacrylate) (PMMA) using the plasma polymerization technique. PMMA films $10 \mu \mathrm{m}$ thick were obtained by Spin-Coating starting from a chloroform solution $(15.36 \% \mathrm{w} / \mathrm{w})$. The films were exposed to the plasma of $\mathrm{CHF}_{3}$ at different gas pressures and exposure times to increase the thickness of fluorinated polymers onto PMMA films. The plasma fluorinated optical films were characterized by gravimetry, FTIR-ATR, contact angle of wetting, SEM and AFM. The surface fluorination of PMMA films can be inferred by the increase in contact angle under all experimental conditions, and confirmed with FTIR-ATR analysis. Gravimetry showed an increase of the fluorinated polymer layer over PMMA films, being $1.55 \mu \mathrm{m}$ thick at 0.7 torr and 40 minutes of plasma exposure. The SEM analysis showed a well-defined layer of fluorinated polymer, with fluorine being detected in the EDS analysis. The film roughness for the fluorinated polymers was around of $200 \AA$, quite satisfactory for a $1.55 \mu \mathrm{m}$ cladding.
\end{abstract}

Keywords: PMMA, plasma fluorination, $\mathrm{CHF}_{3}$ gas.

\section{Introduction}

PMMA has been extensively studied for the numerous applications in the field of coatings, adhesives, sensors, optical devices, biomaterials. PMMA can be deposited by many techniques as plasma polymerization, thermal deposition, RF sputtering, etc ${ }^{[1,2]}$. In optical devices, PMMA shows the best optical properties among transparent polymers, being a very common core material in polymeric optical fibers, waveguides and optical interconnect ${ }^{[3]}$. For this, the use of polymers have been studied due to the intrinsic versatility molecular structure that allows advantageous refractive index modeling for core and cladding, and also to their easy fabrication process or patterning capability ${ }^{[4,5]}$. Low refractive index is a requirement for cladding material and it is usually achieved with fluorinated polymers. Plasma polymerization is the most efficient methods of surface modification, being studied for last one and a half decade. They have yet not been thoroughly explored. Since, polymer tends to react distinctly with each surface modification technique it leaves a wide scope for indepth explorations and novel applications ${ }^{[6,7]}$. Plasma of fluorocarbons has unique capability to etch several inorganic and organic materials as well as to deposit fluoropolymer thin films. The intrinsic versatility of these plasmas reflects their ability to generate two kinds of reactive species, namely fluor atoms and CFx ( $\mathrm{x}=1$, 2 and 3) fragments, which are responsible of the etching of many substrates and of the deposition of a wide range of fluorocarbon coatings ${ }^{[8]}$. Previous work showed the feasibility to use the plasma fluorination process to modify the surface and reduce the refractive index of PMMA films. XPS and FTIR-ATR analysis revealed that a thin layer of a partially fluorinated polymer was deposited on the PMMA films after plasma ${ }^{[9]}$. In this work, plasma fluorinated PMMA optical films were produced by $\mathrm{CHF}_{3}$ plasma. The plasma process variables, gas pressure and exposition time, were explored to achieve increased thicker fluorinated layer onto PMMA films.

\section{Methodology}

PMMA (Plexiglas V052, Rohm and Haas) films were prepared by spin coating (Headway Research, at $1900 \mathrm{rpm}$ and 30s) onto a silicon substrate using a solution of PMMA and chloroform ${ }^{[10]}(15.36 \% \mathrm{w} / \mathrm{w})$. PMMA film thicknesses were around $10 \mu \mathrm{m}$. The PMMA films were exposed to $\mathrm{CHF}_{3}$ gas plasma in a parallel plate reactor $(E N I R F)$ connected to a radiofrequency generator (13.56 MHz). 22 Star Factorial Experimental Design ${ }^{[11]}$ (Table 1), with axial levels $(\sqrt{2})$ and central point, was used to verify the linear or quadratic effect of the plasma variables, gas pressure and time, on the thickness of the plasma deposited polymer. Eleven experiments were carried out with triplicate at the 
Table 1. Factors and levels for $\mathrm{CHF}_{3}$ plasma processing.

$\begin{array}{lccccc} & -\alpha & \text { Lowest level } & \text { Central point } & \text { Upper level } & +\alpha \\ & (\mathbf{- 1 , 4 2 )} & (\mathbf{- 1}) & (\mathbf{0}) & (+\mathbf{1}) & 0.7 \\ (+\mathbf{1 , 4 2})\end{array}$

central point of the star design. Plasma power and gas flow rate were kept at $120 \mathrm{~W}$ and $20 \mathrm{sccm}$, respectively.

The surfaces of the polymeric films, before and after plasma, were characterized using the following techniques:

- FTIR-ATR analysis (Bruker Equinox 55, ATR-PIKE MIRacle with zinc selenate ( $\mathrm{ZnSe}$ ) crystal, $45^{\circ}$ angle, 32 scans);

- Contact angle measurements of surface wetting (Tantec Half-Angle CAM-MICRO), using water as contact liquid at non-saturated conditions $\left(22{ }^{\circ} \mathrm{C}\right.$, H.R. $60 \%$ );

- Gravimetry $\left(10^{-5} \mathrm{~g}\right.$ precision), to estimate thickness of the fluorinated layer on the PMMA films after plasma, using density of known partially fluorinated polymer (PVDF: $\left.\mathrm{d}=1.75-1.80 \mathrm{~g} / \mathrm{cm}^{3}\right)^{[12]}$;

- Scanning electron microscopy (SEM) with Energy dispersive spectroscopy probe (EDS) (LEO 440i);

- Atomic force microscopy (AFM) (AutoProbe CPII).

\section{Results and Discussion}

Polymerization rate may be efficient at high pressures and processing time, this planning was made increasing by some points the gas discharge pressure and time ${ }^{[12]}$. The statistical analysis showed that the process variables pressure and time were significant at $95 \%$ confidence (Equation 1).

$$
\begin{aligned}
\text { thickeness }= & 0.58+0.28 \times X_{1}+0.004 \times X_{1}^{2} \\
& +0.29 \times X_{2}+0.07 \times X_{2}{ }^{2}+0.08 \times X_{1} \times X_{2}
\end{aligned}
$$

As the quadratic terms were not significant, as well as the interaction between pressure and time, the Equation 1 was simplified to Equation 2:

$$
\text { thickness }=0.64+028 \times X_{1}+0.29 \times X_{2}
$$

In which: $X_{1}=\frac{\text { pressure }-0.5}{0.2}$ and $X_{2}=\frac{\text { time }-30}{10}$.

The contact angle measurements in the PMMA surface was $72.0 \pm 2^{\circ}$. The increase of the contact angle values after plasma processing showed surfaces similar to PTFE (polytetrafluoroethylene - angle $\left.110^{\circ}\right)^{[13]}$. However, there weren't significant differences at $95 \%$ confidence at the process conditions investigated. Table 2 shows the results of the mass, thickness and contact angle measurements in the layer deposited by plasma over PMMA films in different process conditions.

Further FTIR-ATR analyses indicated a change concerning the molecular groups of PMMA regarding the fluorinated films. Figure 1 shows the changes involved with different processing times at pressures of 0.5 torr with time variation and Figure 2 shows the changes at different gas discharge pressures within 30 minutes
Table 2. Mass, thickness and contact angles after fluorination processes.

\begin{tabular}{ccccc}
\hline \multicolumn{2}{c}{ Process conditions } & Mass & $\begin{array}{c}\text { Thickness } \\
(\mathbf{m g})\end{array}$ & $\begin{array}{c}\text { Contact } \\
\text { Angle }\left({ }^{\circ}\right)\end{array}$ \\
\hline 0.783 & 30 & 0.97 & 0.85 & 109.6 \\
0.7 & 40 & 2.00 & 1.59 & 104.6 \\
0.7 & 20 & 0.73 & 0.61 & 102.0 \\
0.5 & 44.14 & 0.67 & 0.89 & 110.0 \\
0.5 & 30 & 0.85 & 0.67 & 108.0 \\
0.5 & 30 & 0.60 & 0.68 & 109.6 \\
0.5 & 30 & 0.62 & 0.45 & 113.6 \\
0.5 & 15.86 & 0.46 & 0.38 & 113.6 \\
0.3 & 40 & 0.58 & 0.79 & 109.0 \\
0.3 & 20 & 0.17 & 0.14 & 102.0 \\
0.217 & 30 & 0.16 & 0.15 & 109.0 \\
\hline
\end{tabular}

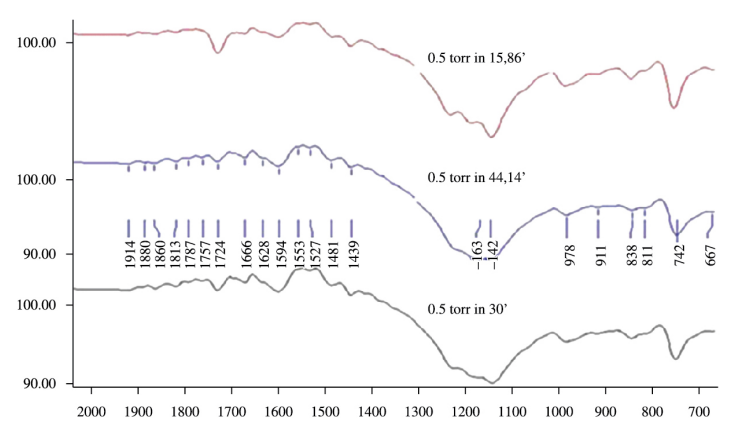

Figure 1. FTIR-ATR spectrums of fluorinated samples (plasma of 0.5 torr in $15.86,44.14$ and 30 minutes).

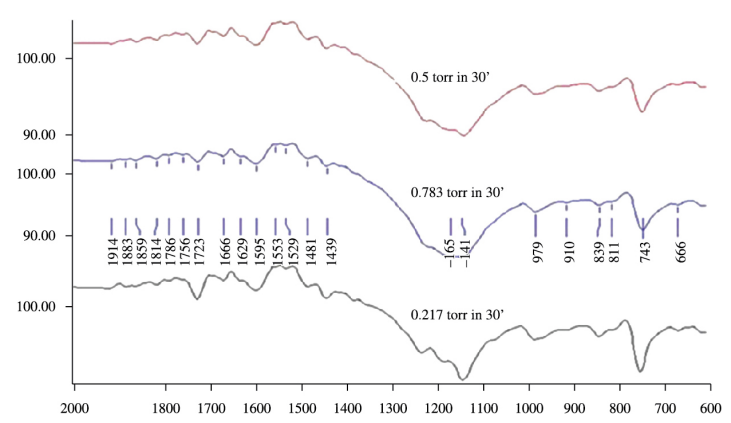

Figure 2. FTIR-ATR spectrums of fluorinated samples (plasma of $0.5,0.783$ and 0.217 torr in 30 minutes).

processing time with pressure variation. For this characterization, the analyses deepness was estimated in $1.14 \mu \mathrm{m}$ and $1.72 \mu \mathrm{m}$ at $1721 \mathrm{~cm}^{-1}$ and $1137 \mathrm{~cm}^{-1}$, respectively. The absorption bands showed up between $980 \mathrm{~cm}^{-1}$ and $1450 \mathrm{~cm}^{-1}$, characteristic of the species CFx. Favia et al. ${ }^{[14]}$ studied FTIR transmittance spectra of films deposited in different conditions and saw sharp 


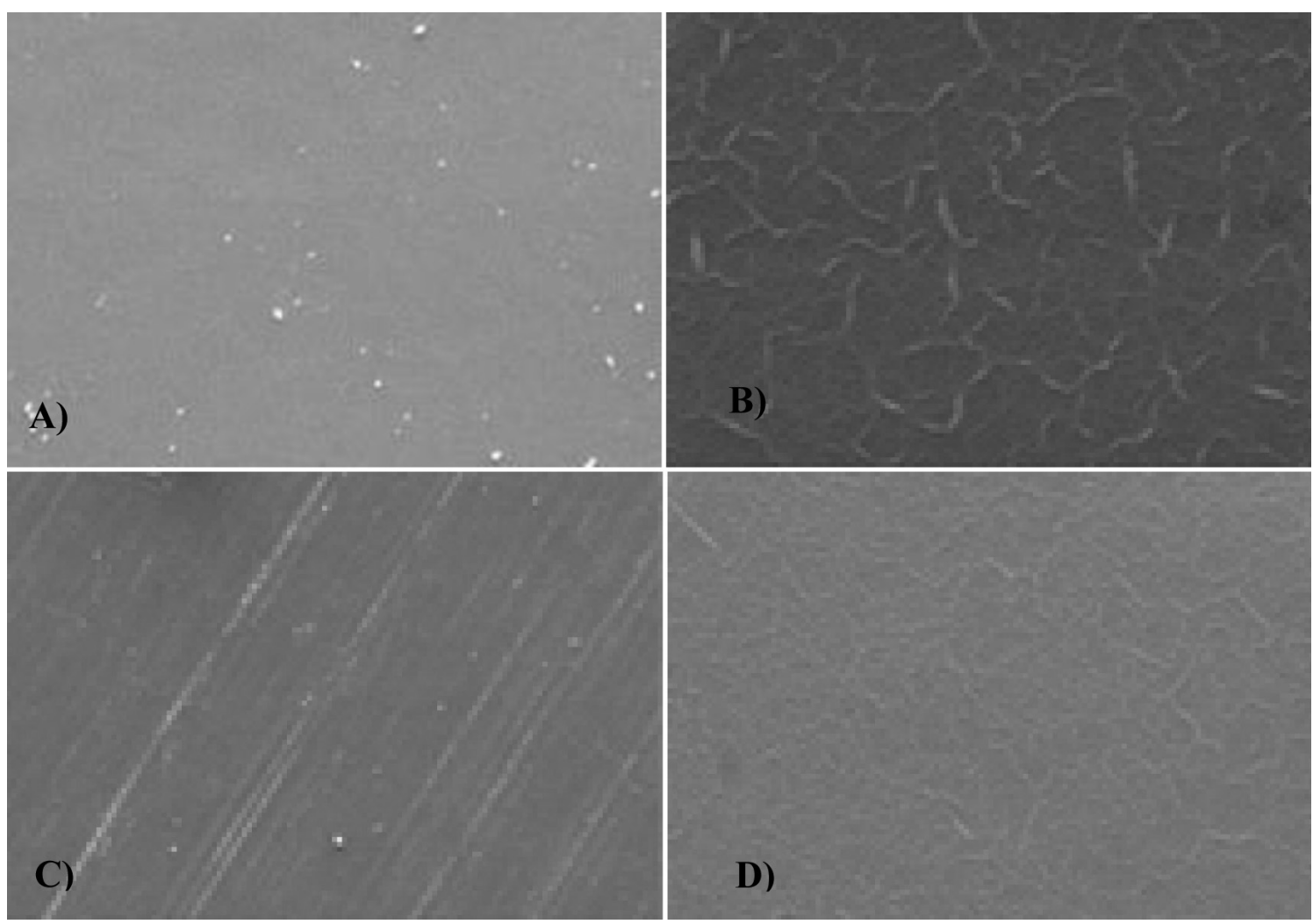

Figure 3. SEM of film surface, with enlargement of 5000x; A) original PMMA and B) 0.783 torr and 30 minutes, C) 0.7 torr and 40 minutes, D) 0.5 torr and 44.14 minutes.

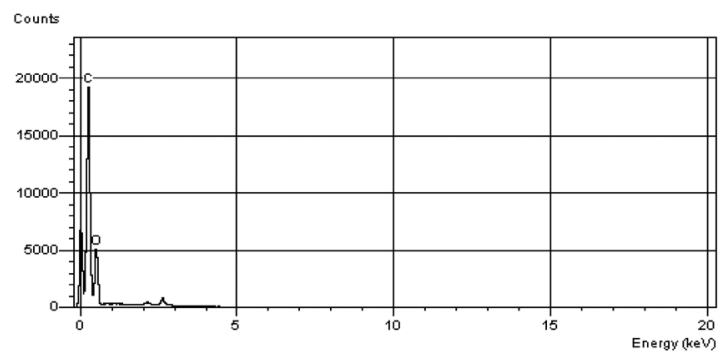

Figure 4. EDS analyses at the central region of a PMMA film.

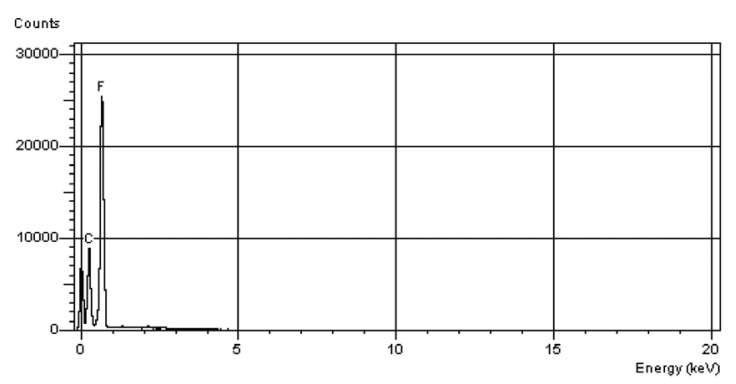

Figure 5. EDS analyses at the central region of a sample after treatment by plasma ( 0.783 torr and 30 minutes).

absorption band at approximately $1180 \mathrm{~cm}^{-1}$ due species $\mathrm{CF}_{2}$. While Bartoli et al. ${ }^{[9]}$ observed a reduction in the relative intensity of the $\mathrm{CH}_{2}$ absorption bands at $1485 \mathrm{~cm}^{-1}$ after treatment by plasma, and also a shift to $1390 \mathrm{~cm}^{-1}$, after 10 minutes by plasma. After plasma treatment, the

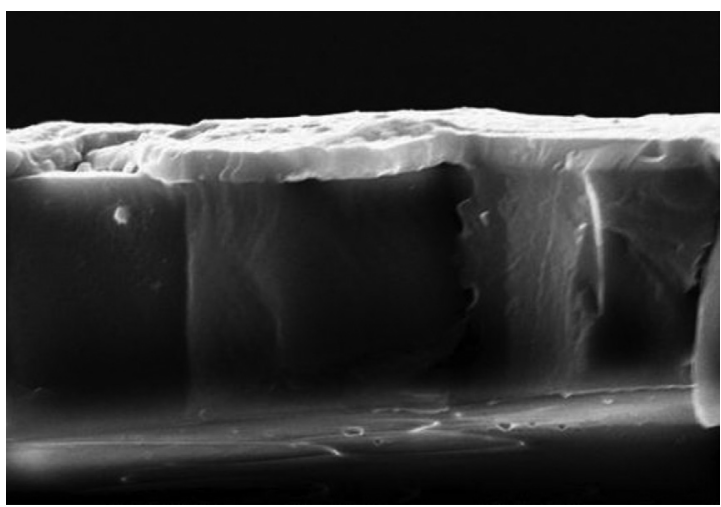

Figure 6. SEM of the cross-section of a sample at process conditions 0.783 torr in 30 minutes.

spectrum of initial PMMA date with the line at $1730 \mathrm{~cm}^{-1}$ attributed to $v(\mathrm{C}=\mathrm{O})$ vibration wasn't significant ${ }^{[15]}$.

By scanning electron microscopy (SEM) it was possible to learn about the surface topography. Figure $3 \mathrm{~A}$ shows the surface of the PMMA polymeric film over the silicon substrate, it was possible see no irregularity during the formation of the polymeric film. Figures 3B-D show the morphology of the fluorinated surfaces at process conditions of 0.783 torr and 30 minutes, 0.7 torr and 40 minutes and 0.5 torr and 44.14 minutes, respectively. Significant morphological chances are present. The morphological built up over the PMMA films may be associated to the plasma reactor conditions. 

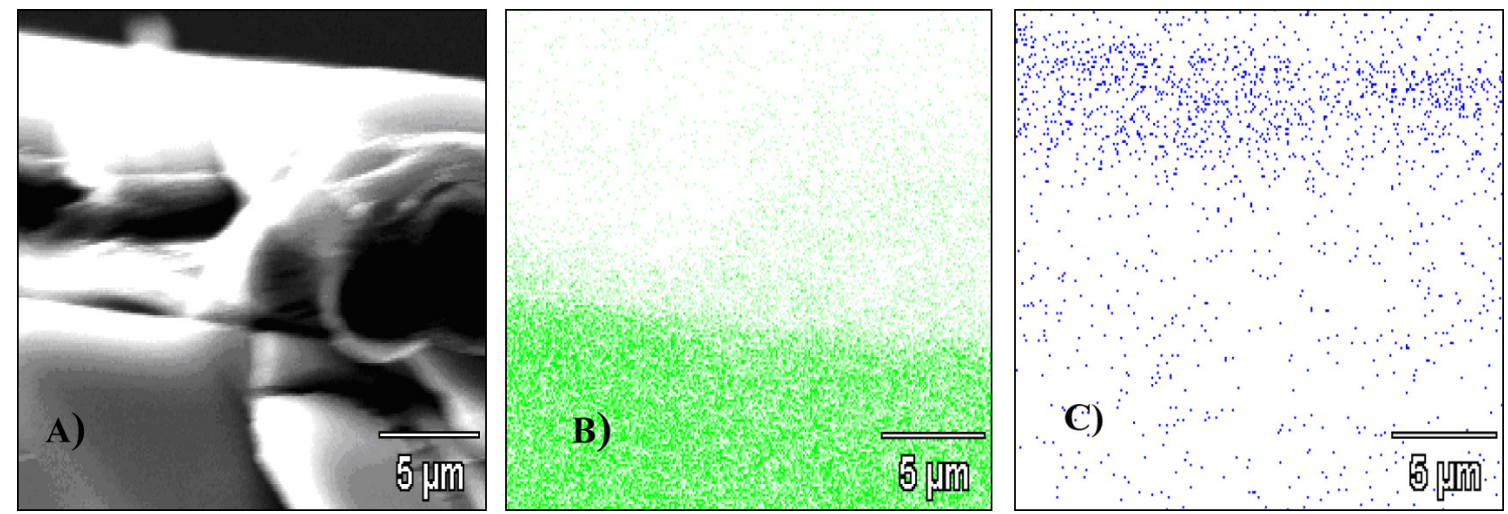

Figure 7. A) SEM of cross-section of a sample which indicate the presence of: B) silicon; C) fluor.

By EDS technique it was possible to observe the chemical characterization of the elements present in the PMMA film and in the fluorinated film. Figure 4 shows the presence of carbon and oxygen on the surface of PMMA films. Fluorinated treatment was confirmed by Figure 5 in which the presence of fluor on the surface of the layer treated by plasma ( 0.783 torr in 30 minutes), which does not occur on the surface of the PMMA film. This was observed at distinct points of several samples at some process conditions, in which fluor was always present followed by carbon. The absence of oxygen indicates the total coating of the PMMA layer by fluorinated layer.

To see the layers produced over the silicon substrate, cross-sectional cuts were made in a few samples. Figure 6 shows the composition of the PMMA film and the fluorinated film at process conditions of 0.783 torr in 30 minutes, at the sample center region. The darkest shades are due to a higher concentration of light chemical elements, as carbon and oxygen. As fluor is heavier, the upper layer presented a clearer region.

Using the EDS probe, the mapping by X-ray was carried out, in order to obtain qualitative information about the elements present in the sample produced in the processing condition of 0.7 torr in 40 minutes. Figure $7 \mathrm{a}$ shows the cross-section of the sample submitted to the analysis. From this image it was possible to recognize the elements present in the substrate, PMMA film and fluorinated film. Figure $7 \mathrm{~b}$, c show the presence the silicon and fluor, respectively. As expected, in the interior region, silicon is in greater proportion for it is a region in which the substrate is present, and fluor is in greater proportion in the upper region, which is a layer deposited by a fluorinated polymer.

The AFM technique was used to check the roughness of the polymeric film after plasma treatment. Figure 8 shows some structures developed from convection cells to PMMA film. By this image it was possible to note a major distance between peaks and valleys $(\sim 297 \mathrm{~nm})$; the rms roughness obtained by this technique was $40 \mathrm{~nm}$. Figure 9 shows the fluorinated film by plasma at process condition of 0.7 torr in 40 minutes which presented the greatest thickness by gravimetry: $1.55 \mu \mathrm{m}$. It is still observed the convection cells produced during the formation of film by spin-coating. This might indicate that the fluorinated layer deposited on the PMMA is

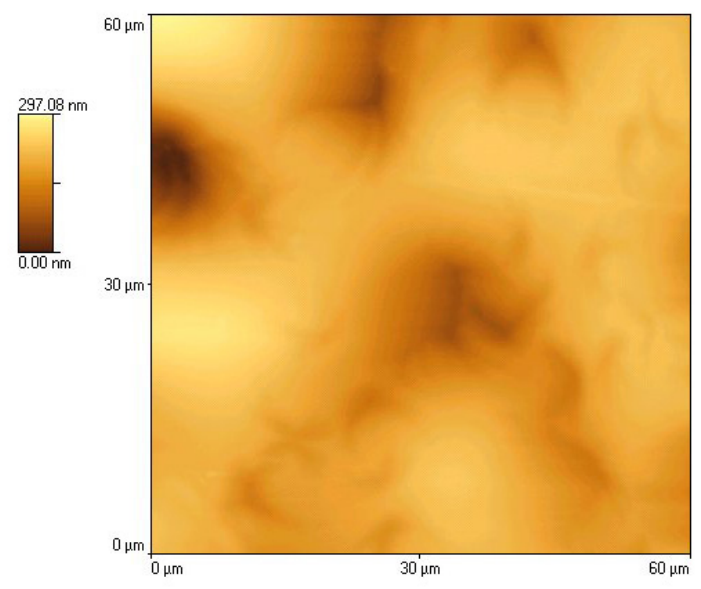

Figure 8. AFM analysis for the PMMA film prepared by spincoating. The rms roughness for this image was $400 \AA$. The analysis area was $60 \times 60 \mu \mathrm{m}$

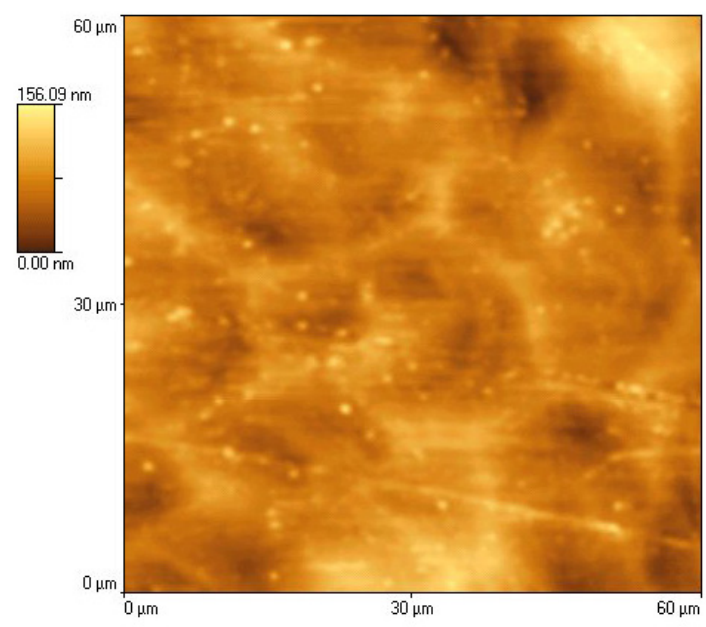

Figure 9. AFM analysis for the fluorinated film prepared at 0.7 torr in 40 minutes. The rms roughness for this image was $400 \AA$. The analysis area was $60 \times 60 \mu \mathrm{m}$.

transparent (characteristic of amorphous polymers), which allows observation of the cells. But even with the formations there are reduction on the distance between peaks and valleys $(\sim 156 \mathrm{~nm})$. For this sample, the rms 


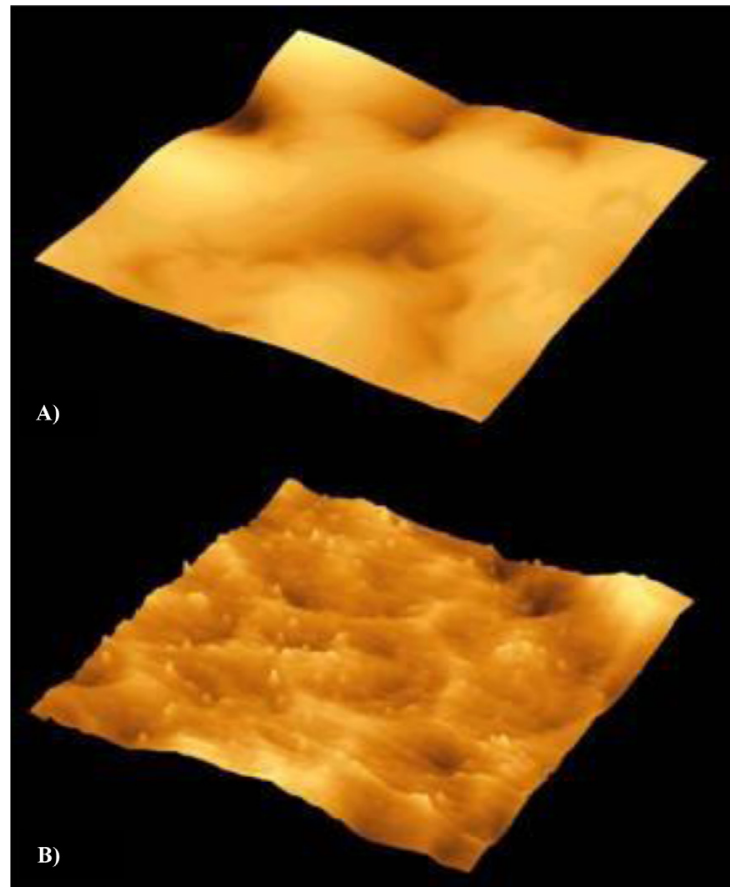

Figure 10. Tridimensional image of the AFM analysis: A) PMMA film - rms roughness of $400 \AA$; B) fluorinated film at process condition 0.7 torr in 40 minutes - rms roughness of $200 \AA$. .

roughness was $20 \mathrm{~nm}$, i.e., half the value of the original PMMA films. Tridimensional images (3D) of the films are presented in Figure 10a (PMMA film) and Figure 10b (fluorinated film), confirming the morphological change of the films surface.

The roughness obtained in this work for the fluorinated sample $(20 \mathrm{~nm})$ may be acceptable for film $1.5 \mu \mathrm{m}$ ticks, exhibiting a ratio of $1 / 70$ for the roughness/thickness ratio. This is well satisfactory for the construction of a waveguide $^{[9]}$. This paper shown that the plasma treatment is effective in altering the functional groups of polymer surfaces without affecting the bulk properties ${ }^{[5]}$.

\section{Conclusion}

PMMA films after exposition to $\mathrm{CHF}_{3}$ showed a significant increase in the contact angle values of the modified surface. The FTIR-ATR analyses indicated a change in the absorption bands typical of PMMA: $\mathrm{C}=\mathrm{O}$ and $\mathrm{C}-\mathrm{O}$, when compared to fluorinated films. This change may be associated to the presence of fluor atoms or to a polymer partially fluorinated over PMMA surface. The objective to reach higher thickness of the fluorinated layer on the PMMA film was reached. Fluorinated films $1.55 \mu \mathrm{m}$ tick can be employed for cladding in waveguides or polymeric optical fibers. By SEM the microstructures on the fluorinated film surface were observed, proving the presence of fluor on the surface of the films treated by plasma observing the cross-section. The AFM showed the reduction of the roughness of the optical films after plasma treatment compared with the original PMMA films. These results indicate the possibility of modifying the PMMA surface by deposition of a partially fluorinated polymeric layer with adequate thickness using $\mathrm{CHF}_{3}$ plasma.

\section{References}

1. Amor, S. B.; Baud, G.; Jacquet, M.; Nanse, G.; Fioux, P. \& Nardin, M. - Appl. Surf. Sci., 153, p.183 (2000).

2. Bodas, D. S. \& Gangal, S. A. - Mater. Lett., 59, p.2907 (2005).

3. Imamura, S.; Yoshimura, R. \& Izawa, T. - Elect. Lett., 27, p.1343 (1997).

4. Emslie, C. - J. Mater. Sci., 23, p.2293 (1998).

5. Park, S. J.; Cho, K. S. \&Choi, C. G. - J. Coll. Inter. Sci., 258, p.426 (2003). http://dx.doi.org/10.1016/S00219797(02)00094-2

6. Inagaki, N. - "Plasma Surface Modification and Plasma Polymerization",Technomic Publishing Company Inc (1996).

7. Bodas, D. S.; Desaib, S. M. \& Gangal, S. A. - Appl. Surf. Sci., 245, p.190 (2005).

8. Fanelli, F.; Fracassi, F. \& D’Agostino, R. - Surf. Coat. Techn., 204, p.1784 (2010).

9. Bartoli, J. R.; Costa, R. A.; Verdonck, P.; Mansano, R. D. \& Carreño, M. N. - Polímeros, 9, p.55 (1999). http://dx.doi. org/10.1590/S0104-14281999000400025

10. Ceschin, A. M.; Sales, M. J. A. \& Pereira, N. S. - Polímeros, 22, p.389 (2012).

11. Barros Neto, B.; Scarminio, I. S. \& Bruns, R. E. - "Como fazer experimentos - aplicação na ciência e na indústria", Bookman, São Paulo (2010). PMCid:PMC2992189.

12. Padilha, G. S.; Giacon, V. M. \& Bartoli, J. R. - Exacta, 8, p.18 (2010).

13. D’Agostino, R.; Colaprico, V.; Favia, P.; Fracassi, F. \& Palumbo, F. - Rev. Bras. Aplic. Vácuo, 20, p.45 (2001).

14. Favia, P.; Cicala, G.; Milella, A.; Palumbo, F.; Rossini, P. \& D’Agostino, R. - Surf. Coat. Tech., 169-170, p.612 (2003).

15. Kondyurin, A. \& Bilek, M. - Nucl. Instrum. Meth. Phys. B., 269, p.1369 (2011).

Received: 05/14/13 Accepted: 06/13/13 